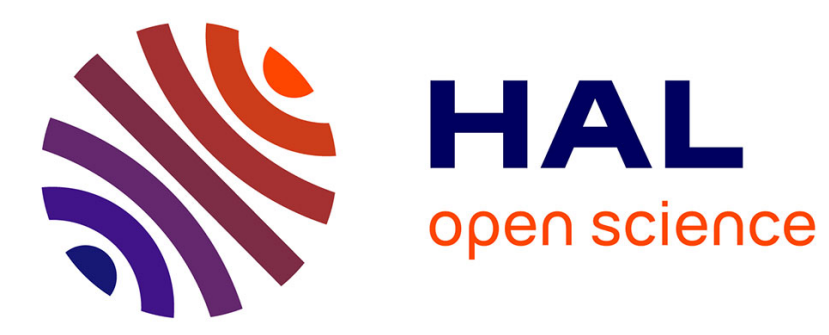

\title{
Impact of the en echelon fault connectivity on reservoir flow simulations
}

\author{
Charline Julio, Guillaume Caumon, Mary Ford
}

\section{To cite this version:}

Charline Julio, Guillaume Caumon, Mary Ford. Impact of the en echelon fault connectivity on reservoir flow simulations. Interpretation, 2015, 3 (4), pp.SAC23-SAC34. 10.1190/INT-2015-0060.1 . hal01281809

\section{HAL Id: hal-01281809 \\ https://hal.univ-lorraine.fr/hal-01281809}

Submitted on 27 Feb 2018

HAL is a multi-disciplinary open access archive for the deposit and dissemination of scientific research documents, whether they are published or not. The documents may come from teaching and research institutions in France or abroad, or from public or private research centers.
L'archive ouverte pluridisciplinaire $\mathbf{H A L}$, est destinée au dépôt et à la diffusion de documents scientifiques de niveau recherche, publiés ou non, émanant des établissements d'enseignement et de recherche français ou étrangers, des laboratoires publics ou privés. 


\title{
IMPACT OF THE EN-ECHELON FAULT
} CONNECTIVITY ON RESERVOIR FLOW

\section{SIMULATIONS}

${ }_{4}$ Charline Julio $^{1}$, Guillaume CAUmon ${ }^{1, *}$, and Mary ForD ${ }^{2}$

${ }^{1}$ GeoRessources, Université de Lorraine-ENSG/CNRS/CREGU, 2 rue du Doyen Marcel Roubault, Vandoeuvre-lès-Nancy F-54518, France

${ }^{2}$ CRPG, Université de Lorraine-ENSG/CNRS, 15 Rue Notre Dame des Pauvres, Vandoeuvre-lès-Nancy F-54501, France

${ }^{*}$ Corresponding author. Tel.: +333835964 40. Fax: +333835964 60. E-mail address: Guillaume.Caumon@ensg.univ-lorraine.fr

July 10, 2015

\begin{abstract}
Limited resolution and quality of seismic data and time requirements for seismic interpretation can prevent a precise description of the connections between faults. We focus on the impact of the uncertainties related to the connectivity of en-echelon fault arrays on fluid flow simulations. We use a set of one hundred different stochastic models of the same en-echelon fault array. These fault array models vary in number of relay zones, relative position of fault segments, size of overlap zones and number of relay faults. We
\end{abstract}


automatically generate a flow model from each fault array model in four main steps: (1) stochastic computation of relay fault throw, (2) horizon building, (3) generation of a flow simulation grid, and (4) definition of the static and dynamic parameters. Flow simulations performed these stochastic fault models with deterministic petrophysical parameters entail significant variability of reservoir behavior, which cannot always discriminate between the types of fault segmentation. We observe that the simplest interpretation consisting of one fault significantly yields significantly biased water cut forecasts at production wells. This highlights the importance of integrating fault connectivity uncertainty in reservoir behavior studies.

\section{Introduction}

During the interpretation of compartmentalized reservoirs, the characterization of fault connectivity is often critical to match production history and make reasonable forecasts of reservoir performance (e.g., Jolley et al. (2007)). In this context, fault connectivity concerns not only the large-scale pattern of faults, which can originate from several tectonic episodes (Sanderson and Nixon, 2015), but also the phenomenon of en-echelon faults, which results from the growth, overlap and linkage of several fault segments, see for instance Peacock and Sanderson (1991); Cowie and Scholz (1992); Cartwright et al. (1995); Childs et al. (1995); Fossen and Hesthammer (2000); Walsh et al. (2003); Giba et al. (2012).

In the subsurface, the characterization of these zones typically relies of 3D seismic data but may be limited by the seismic resolution and artifacts (Thore et al., 2002). Indeed, the relatively wide damage zones around overlapping fault segments (Kim et al., 2004; Rotevatn et al., 2007) tends to diffract seismic waves and make 
relay fault interpretations very delicate. Significant literature about the description and statistics about en-echelon fault arrays may be used to drive the fault segment identification (e.g., Cartwright et al. (1995); Walsh et al. (2003); Soliva and Benedicto (2004)). However, in practice, limited interpretation time is also a source of uncertainties, which can be exacerbated by the insufficient use of geological concepts (Kattenhorn and Pollard, 2001; Bond et al., 2007; Bond, 2015).

The impact of fault overlap zones on reservoir behavior has been studied by several authors (Bense and Van Balen, 2004; Micarelli et al., 2006; Manzocchi et al., 2008a; Rotevatn et al., 2009a,b; Manzocchi et al., 2010; Fachri et al., 2013). Relay zones are often described as flow conduits between two fault blocks which would otherwise be isolated (Bense and Van Balen, 2004; Manzocchi et al., 2010). However, the complexity and diversity of relay zones make it very challenging to define a general quantitative rule about their impact on fluid flow (Manzocchi et al., 2010; Bastesen and Rotevatn, 2012). Indeed, the overlap zones are usually associated with intense brittle deformation that can lead to the formation of a relay fault. Figure 1a shows a simplified view of a relay fold, which may be affected by fractures and compaction bands, while Figure 1b shows a more mature structure where the relay has been breached by a relay fault. These two configurations correspond to soft-linked segments (Figure 1a) and hard-linked segments (Figure 1b). Such relay structures can act as barriers or drains depending on the fluid types, the rock nature and the amount and type of deformation. Geometrically, the existence or absence of a connecting breach fault in an overlap zone can have a large effect on the juxtaposition of stratigraphic units on either sides of the fault zone. As a first approximation, the juxtaposition of two high permeability units increases the connectivity between two fault blocks, whereas a reservoir unit can be sealed due to its juxtaposition 
with low permeability units. However, more complex effects can occur due to the possible occurrence of cataclasic deformation bands or the smearing of shale in the fault planes.

Representing the effects of all these features of reservoir flow model is challenging, especially for multi-phase flow, see Manzocchi et al. (2010). A possible avenue is to integrate the effects of these features as deterministic or stochastic perturbations of transmissibilities between neighboring control volumes in the flow simulation grid. For example, Manzocchi et al. (2008a) capture the effects of small fault throw changes in a pillar-based reservoir grid and simulate relay zone frequency based on the mapped throw. In this paper, we instead explicitly create a new grid for each realization to capture the uncertainties.

For this, we build on a recent stochastic method that generates a set of possible segmentation configurations from a composite fault interpreted as one continuous structure (Julio et al., 2015). A segmentation configuration means here a 3D geometric model composed of overlapping segments separated by breached or intact relay zones. The method uses the orientation variations of the composite fault as indicators of the occurrence of relay zones. The models generated by this method mainly vary in number of fault segments, relative position of the segments, size of overlap zones and number of relay faults. From each fault model and horizon data, we create a synthetic numerical flow model made of a flow simulation grid associated with static and dynamic parameters.

As compared to transmissibility-based approaches, our method is not a priori constrained by a reference flow simulation grid and allows considering the effects of fault segments on the static accumulations. It probably allows for more variability in the simulated geometry of relay zones, by exploiting the capabilities of recent 
advanced gridding algorithms to integrate more complex fault descriptions than generally possible in pillar grids (Gringarten et al., 2008; Mallison et al., 2014). We also believe such an explicit geometric representation could be interesting in the future to integrate the effects of juxtaposition and damage zones on other physical processes (e.g., geomechanics or seismic wave propagation). In the context of the present paper which uses stair-step corner-point geometry flow grids, the method is suitable for local flow models or global flow models in which the separation between fault segments is larger than the areal grid resolution, as for instance in Rotevatn et al. (2009a).

In the following, we present the method to stochastically simulate relay zones and apply it to a reservoir model. Our approach extends the previous work by Julio et al. (2015). In particular, we capture the fault juxtaposition uncertainties in the relay zones by simulating possible throws of the relay fault, and we generate grids whose topology and geometry may vary for each realization. This allows us to perform a flow sensitivity analysis on all the simulated models to study the relationships between the types of segments and the flow behavior.

[Figure 1 about here.]

\section{Automatic generation of segmented reservoir mod- els}

Reservoir modeling generally aims at transforming geophysical and borehole interpretations into a 3D reservoir flow grid. Standard workflows are roughly composed of four main successive steps. (1) The first step consists of building a reservoir structural model in which the geological interfaces, such as faults, horizons and un- 
conformities, are represented as 3D surfaces (Mallet, 1988; Caumon et al., 2009). (2) Then, a corner-point grid widely used in reservoir simulation provide a 3D mesh of the reservoir volume. (3) From well data, the petrophysical properties of the rock are computed using deterministic interpolations or stochastic simulations (Pyrcz and Deutsch, 2014). (4) Flow simulations may then be finally performed based on finite volume methods.

In this paper, we combine a new method to create a stochastic description of a 3D segmented fault (Julio et al., 2015) with standard existing methods for the steps 1-3. This section starts with a description of the data set used in our study and generated by the method of Julio et al. (2015). Then, we present the strategy applied to model the horizons. Indeed, as no horizon data points are available in relay zones, we propose to stochastically estimate the throw of the relay faults, and to use this estimation to constrain the interpolation of the horizon geometry in relay zones. Then, we explain how we create a conventional reservoir simulation grid for each of the stochastic structural models.

\section{Data set and stochastic fault model generation}

The proposed method is applied on a Middle East case study whose orientation, reservoir depth and fluid contact depth have been modified for confidentiality reasons. The data set used to model the reservoir is composed of: two horizon point sets and a normal fault $\mathcal{F}$ (Figure 2). The two horizon point sets and the fault $\mathcal{F}$ have been interpreted from a relatively low-quality onshore 3D seismic data set. These two horizons delimit a reservoir formation whose thickness is about $180 \mathrm{~m}$ and cover an area of $11 \mathrm{~km}$ by $1.1 \mathrm{~km}$. The fault $\mathcal{F}$ is a composite normal fault whose segmentation could not be clearly identified from the seismic data. The global geometry of the 
reservoir is a monoclinal horst striking N 140 (Figure 2). The fault $\mathcal{F}$ strikes parallel to the main reservoir orientation and may be a potential flow barrier between the upper compartment and the lower compartment whose pressure is supported by an active aquifer located in the SW. The uncertainties associated to the exact location of this fault can also impact the OOIP because the top depth of footwall block is close to the oil-water contact depth. Therefore, small fault throw perturbation has a relatively large impact on reservoir closure. In the reservoir zone, the orientation of the fault $\mathcal{F}$ locally shows some abrupt variations in the strike direction.

Julio et al. (2015) quantify these strike variations and interpret them as possible indicators of overlap zone occurrence. Their stochastic simulation method simulates possible fault segments from approximately planar areas in the fault surface using probabilistic descriptions about relative segment size and overlap/size relationships. This method has been applied to generate one hundred segmentation models of the fault $\mathcal{F}$. These models may have different number of fault segments, size of overlap zones, relative position of segments and segment geometry. The occurrence or not of a relay fault in an overlap zone is determined from the ratio between overlap (overlap zone length) and separation (overlap zone width). If this ratio is superior to a stochastically-chosen threshold, a relay fault is modeled in the middle of the corresponding overlap zone (Soliva and Benedicto, 2004). In the vertical direction, the relay faults have the same extent as the associated overlapping segments. Figure 3 summarizes the generated configurations among the one hundred downscaled models of the fault $\mathcal{F}$. The three main obtained segmentation configurations are: $28 \%$ are two hard-linked left-stepping segments, $25 \%$ are two soft-linked right-stepping segments, $16 \%$ are three soft-linked segments (Figure 3).

The downscaling method introduced by Julio et al. (2015) deals only with the 
uncertainty related to faults (treated as slip surfaces), without consideration of the displacement in the relay zone that may be poorly-imaged on the seismic data. Therefore, we now present a new algorithm to manage uncertainties on the throw of relay faults, which can have a large impact on flow (Manzocchi et al., 2010).

[Figure 2 about here.]

[Figure 3 about here.]

\section{Stochastic computation of relay fault throws}

3D horizons are built by interpolation of input point sets extracted from 3D seismic data. However, in the majority of cases, the low quality of seismic data does not allow the characterization of the horizon geometry in overlap zones. In models with a continuous ramp in the relay, the geometry is computed by interpolation between horizon picks available on either side of the ramp. This is essentially similar to making a thin-plate assumption of the horizon geometry within the relay ramp. In models where the ramp is breached, the relay fault throw must be estimated before interpolating the horizon geometry.

For this, we propose to simulate points that will be used as interpolation constraints for horizon building in breached relay zones. Consider a horizon denoted $\mathcal{H}$ and a relay fault denoted $\mathcal{R}$. The method computes the vertical displacement (denoted $d$ ) of the horizon $\mathcal{H}$ in the neighborhood of the relay zone, i.e. the total displacement away from the relay fault $\mathcal{R}$. This displacement $d$ is computed from a sphere centered on the relay fault center and whose radius is input by the interpreter (Figure 4). The points associated with the horizon $\mathcal{H}$ inside the sphere are selected and the algorithm differentiates the points located in the footwall of the relay fault 
from the ones in the hanging wall. The mean difference in depth between these two point sets gives an estimate of the vertical displacement $d$. If the sphere contains no data point, it is enlarged until points are found. This methodology calls for reliable horizon picks in the vicinity of the fault, for example by eliminating potentially erratic points within a certain distance of the fault surface.

The vertical displacement $d$ corresponds to the sum of the throw $\left(d_{\text {Fault }}\right)$ of the relay fault $\mathcal{R}$ and of the vertical displacement $\left(d_{\text {Fold }}\right)$ associated with the ramp fold, which is also termed "throw deficit" (Faure Walker et al., 2009). The ratio between the relay fault throw $d_{\text {Fault }}$ and the total displacement $d$ at the relay fault center is related to the maturity of the relay zone. In our method, we use a probability distribution from which this ratio can be sampled to generate a particular realization. In the vertical direction, this ratio is assumed to be maximal at the relay fault center and to decrease vertically towards the relay fault tips. Consider a function $\beta$ that characterizes the ratio evolution (Figure 4a), and a parameter $v$ that is the signed difference between the relay fault center depth and the mean depth of the horizon $\mathcal{H}$ inside the sphere. The value of the relay fault throw associated with the horizon $\mathcal{H}$ is defined as:

$$
d_{\text {Fault }}=\beta(v) \cdot d
$$

The hanging wall and the footwall may differently accommodate the brittle deformation. Therefore, we define a partition factor $\gamma$ (between 0 and 1) as the proportion of throw accommodated by the footwall (Georgsen et al., 2012; Laurent et al., 2013). Thus, the values of throw in the footwall and in the hanging wall are:

$$
d_{\text {Fault }}^{F O O T}=\gamma \cdot d_{\text {Fault }},
$$




$$
d_{\text {Fault }}^{H A N G}=(1-\gamma) \cdot d_{\text {Fault }}
$$

The values $d_{\text {Fault }}^{F O O T}$ and $d_{\text {Fault }}^{H A N G}$ are used to add synthetic horizon points conditioning the relay fault throw (Figure $4 \mathrm{~b}$ ). These new stochastic points and the initial point sets are used to interpolate the horizon geometry (Figure $4 \mathrm{~b}$ ). In terms of impact of these parameters, the value of $\beta$ directly affects the geometry and the juxtaposition of rock units across the fault zone. The value of $\gamma$ has probably less influence because if only affects the depth of the layers in the fault zone and not the juxtaposition.

In our application, the parameter $\beta(0)$ characterizing the ratio between the relay fault throw and the total vertical displacement at the fault center is randomly chosen from a Gaussian distribution defined by a mean and a standard deviation equal to 0.5 and 0.08 , respectively. This means that the relative throw deficit due to the relay is assumed to vary between $34 \%$ and $56 \%$ of the global throw $d$ in $95 \%$ of the cases. The choice of these values are here arbitrary, so further studies should be made to define $\beta(0)$ according to the lithology and to the intensity of the deformation. The partition factor $\gamma$ is also chosen from a Gaussian distribution defined by a mean and a standard deviation equal to 0.5 and 0.08 , respectively. Indeed, as the relay faults have been simulated in the middle of the overlap zones, we make the parsimonious assumption that, on average, the footwall and the hanging wall accommodate about the same quantity of deformation.

[Figure 4 about here.] 


\section{Grid computation and petrophysical modeling}

Based on the API (Application Programming Interface) of the geomodeling software Gocad-SKUA, we have developed a plugin which implements the stochastic segmented fault downscaling approach described above and then automatically generates a corner-point grid honoring these structures (Figure 5a). The gridding method generates stair-step corner-point grids as described in Gringarten et al. (2008). Essentially, the reservoir grids honor the stratigraphic layering and maintain sub-orthogonal cell shapes suitable for conventional reservoir simulation. As a result, the faults are discretized as stair-step cell faces.

This allows us to efficiently build grids from a large set of stochastic structural models. The grid dimensions are globally equal to $11 \mathrm{~km} \times 3 \mathrm{~km} \times 0.8 \mathrm{~km}$. Each grid is composed of the same number of cells $(230 \times 30 \times 20=230,000)$, yielding an average grid block size of $48 \times 122 \times 8.6 \mathrm{~m}$. However, due to the topological and geometrical changes of the fault array, the number of active cells slightly varies in each model and is approximately equal to 112,000 (cells are considered dead if their pore volume is lower than $100 \mathrm{~m}^{3}$ ).

To isolate the effect of fault uncertainty on flow behavior, we have used the same synthetic petrophysical model in all the simulated grids. This petrophysical model assumes laterally continuous but vertically layered rock types as could exist for instance in turbiditic lobes. The Net-To-Gross values have been chosen constant and equal to 0.8 . The porosity and the permeability have been simulated as stationary Gaussian random fields using a Sequential Gaussian Simulation (Figure 5b). We used spherical variogram models with ranges of $5 \mathrm{~km}, 3 \mathrm{~km}$ and $5 \mathrm{~m}$ in the $\mathrm{N} \mathrm{140,}$ N 230 and vertical directions, respectively. The porosity approximately follows a 
normal distribution of average 0.13 and standard deviation 0.02 . The horizontal permeability is isotropic and approximately follows a triangular distribution of minimum $200 \mathrm{mD}$, mode $600 \mathrm{mD}$ and maximum $1500 \mathrm{mD}$. It has a 0.98 rank correlation coefficient with the porosity values. The $K_{V} / K_{H}$ ratio is taken constant and equal to 0.001 to compensate for the relatively coarse vertical grid resolution.

\section{Flow simulations results and interpretations}

\section{Fluid flow simulation parameters}

The en-echelon fault array completely crosses the reservoir from NW to SE (Figure 5). The faults are considered as partially sealing with transmissibility multipliers assumed constant and equal to 0.05 .

Two initial fluids, water and oil, are initially present in the reservoir. The initial water saturation in the oil zone is 0.05 and the residual oil saturation after water flooding is 0.24 . The water oil contact vertically crosses the fault array (Figures 6 and 7). At the SW, an aquifer maintains the reservoir pressure during oil production (Table 1).

The reservoir production scenario takes advantage of aquifer pressure support and only uses two production wells $w_{1}$ and $w_{2}$, located in the NE near the top of the structure (Figure 5, Table 1). In the initial state, all the well perforations are located in the oil zone. The wells are controlled by the oil production rate but completions may be shut down if the bottom-hole becomes lower than an input threshold (Table $1)$.

[Figure 5 about here.] 


\section{Fault segmentation impact on flow simulations}

From the 100 downscaled models, we obtained 93 flow simulations. The seven other models failed during the automatic grid generation step or the flow simulations. In this section, we compare the oil saturation and the water cut evolution of the different segmented reservoir models (Figures 9, 7, 10, 11).

Range of initial conditions. The stochastic estimate of relay fault throws and the interpolation between point sets involve some variations on the initial oil in place value of the stochastic downscaled models. The mean and the standard deviation are equal to $176.8 \mathrm{Msm}^{3}$ and $1.710 \mathrm{Msm}^{3}$, respectively (Figure 8). These variations can be explained because the local throw and reservoir top depth variations directly affect the gross rock volume above the oil-water contact. The model composed of the single fault $\mathcal{F}\left(177.3 \mathrm{Msm}^{3}\right)$ is close to the mean (Figure 8).

[Figure 8 about here.]

Range of dynamic responses. After 30 years of production, the water cut values vary from 0.13 to 0.91 in well $w_{1}$ and from 0.15 to 0.91 in well $w_{2}$ (Figure 10ab). This very high dispersion of water-cuts highlights the significant impact of fault segmentation on reservoir behavior. In the reservoir model composed of the continuous fault $\mathcal{F}$ (before downscaling), the water-cut values are respectively equal 
to 0.37 and 0.85 in wells $w_{1}$ and $w_{2}$ after 30 years of production (Figure 9 ). These two values are close to the extreme values of the statistics of downscaled models. Indeed, the deterministic water cut value (0.37) for the well $w_{1}$ is inferior to the 10th percentile (0.43) of the stochastic models, and, on contrary, the deterministic water cut value $(0.85)$ for the well $w_{2}$ is superior to the 80 th percentile $(0.81)$ of the stochastic models. Thus, performing flow simulations on the fault $\mathcal{F}$ without consideration of the segmentation uncertainties may lead to major approximations in dynamic behavior predictions, and therefore in oil production estimates.

Fault segmentation configurations and flow responses. One of the outputs of the downscaling method is the probability of segmentation configurations (Figure 3). These configurations can be seen as samples of discrete structural scenarios. Could these scenarios be discriminated from actual reservoir production data? To answer this question, for each of these configurations, we analyze the water cut evolution and the breakthrough time (considered occurring when the water fraction reaches 0.01 at producer wells).

Figure 10c-d shows the evolution for models composed of two hard-linked leftstepping segments and of two soft-linked right-stepping segments. In the well $w_{1}$, the water cut at a given time is globally higher for two soft-linked than for two hardlinked segments. The opposite result is clearly observed for the well $w_{2}$. Figure 11 shows statistics about water breakthrough times for the main different configurations, which confirm the previous observations. In the well $w_{1}$, the water breakthrough is earlier for two soft-linked segments than for two hard-linked segments (Figure 11a). The water delay is likely due to the relay fault that slows down the percolation of water across the ramp (Figure $7 \mathrm{~b}$ ). Conversely, in the well $w_{2}$, the water breakthrough is earlier for two hard-linked segments than for two soft-linked 
segments (Figure 11b). This can be explained by the relatively large water production in the well $w_{1}$ in the case of two soft-linked segments, allowing the well $w_{2}$ to remain longer in the oil zone (Figure $7 \mathrm{~b}-\mathrm{d}$ ).

We can also analyze the difference on dynamic behavior between three soft-linked segments (no ramp is breached) and two soft-linked segments (Figures 7c-d, 10e-f and 11). In the well $w_{1}$, the water breakthrough is, on average, earlier for threesegment models than for two-segment models (Figure 11a). This can be explained by the small throw of the central segments in three-segment configurations, leading to a significant juxtaposition area of reservoir layers (Figure 7c). As these segments are only partially sealing, they act as major preferential flow paths. In the well $w_{2}$, no clear relationship appears between flow trends and segmentation patterns (Figures 10f and 11b).

Similarly, the configurations composed of three soft-linked segments are hardly differentiated using the water cut evolution (Figures 10g-h and 11). Nonetheless, as the models with such configurations are few, the corresponding statistics should be cautiously analyzed. Overall, the configurations composed of soft-segments are difficult to differentiate one from another. However, the configuration composed of two hard-linked left-stepping segments presents a dynamic behavior different from the other configurations analyzed in this section (Figure 11).

While segmentation patterns affect flow paths in the reservoir, a high variability of flow responses is also observed among models of a same pattern (Figures 10, 11). This is likely due to the large vertical variability of the permeability, which involves large changes in fault transmissibility as the throw changes. This may also stem from geometric variations of the segments, relay zone locations and local layer dip changes. 


\section{Discussion and conclusions}

This paper presents a study of fault segmentation effects on flow simulations using a sample of possible configurations computed stochastically from a large-scale composite fault. For this, we have developed a new process that automatically generates structural models, flow simulation grids and petrophysical properties. This provides an alternative to methods which perturb the transmissibilities of a reference pillar-based reservoir simulation grid.

Several improvements could be added in the stochastic simulation method. At present, we have made the choice to always use the same geometric rules to generate breach faults. As a result, simulated breach faults always have the same relative strike as compared to the fault segments. This could be made variable, as it has been shown to have an impact on strain localization during fault growth (Faure Walker et al., 2009). Also, the downscaling method does not presently use throw estimation to constrain the number of segments. As discussed in Julio et al. (2015), this information could either be integrated in the stochastic segmentation method or used as a criterion to assess the likelihood of the stochastic models after the simulation.

While the present study focuses on uncertainties related to fault connectivity, several additional sources of uncertainties could be addressed in future developments. From a geometric standpoint, the horizons have been generated without consideration of interpretation and velocity uncertainties (e.g., Abrahamsen (1992); 
Thore et al. (2002)). These sources of uncertainty could be incorporated into the stochastic process, for instance by the perturbation of the depth and thickness of the generated reservoir grids. A loop back computing synthetic seismic models from the realizations and comparing with the actual data could also be useful to rank the various stochastic interpretations generated by our approach.

In terms of petrophysics, the petrophysical and dynamic parameters were kept the same in all the generated reservoir models to highlight the impact of structural geometry uncertainties on flow simulations. However, a complete reservoir uncertainty study would definitely need to jointly assess the effects of fault segmentation and petrophysical uncertainty, by using also multiple petrophysical models. Moreover, the effects of the various structural configurations on capillary rock properties in the fault and relay zones should in principle be overprinted to the depositional petrophysical model, both in the deformed neighborhood of the fault (Rotevatn et al., 2009b; Fachri et al., 2013) and on the fault surfaces themselves (Manzocchi et al., 1999, 2002; Myers et al., 2007). Adding these relationships to the flow models could be interesting to better approach the true dynamic flow behavior of the simulated relay zones.

As compared to our approach, geometrical upscaling (Manzocchi et al., 2008b, 2010) deals with relay uncertainty by direct editing of transmissibilities on a pillar grid, assuming that faults are vertically aligned on grid pillars. The methodology proposed in this paper makes fewer assumptions about the fault geometry but leaves the discretization problems to the chosen stair-stepped gridding algorithm (Gringarten et al., 2008). Although the details of both methods vary, they are essentially both limited by the reservoir grid resolution, which can only represent the effect of the fault features as constant permeability within each grid block or as a 
transmissibility multiplier between rock volumes. At this point, in spite of its pillar approximation, geometrical upscaling may be more accurate than our present implementation because it does integrate fault features in the computation of transmissibility multipliers. However, the possible effect of grid distortions in pillar grids may be a source of artifacts. Further comparison between our approach and geometrical upscaling is difficult because it strongly depends on implementation, so would certainly call for further studies. Nevertheless, other types of gridding algorithms could be used in our approach, such as the cut-cell method Mallison et al. (2014) for flow simulation. We also suggest that our workflow clears the path for more accurate modeling of coupled flow and mechanical processes in complex fault zones. Therefore, future work will aim to connect the stochastic workflow with unstructured gridding methods (Mustapha et al., 2011; Merland et al., 2014; Pellerin et al., 2014; Zehner et al., 2015) and advanced multiphysics codes (e.g., Matthäi et al. (2007); Paluszny et al. (2007)).

Nonetheless, the observed impact of fault segmentation on reservoir behavior confirms that relay zone uncertainties can be consequential for dynamic reservoir forecasts. This finding is consistent with many previous studies (e.g., Rotevatn et al. (2009a); Manzocchi et al. (2007); Myers et al. (2007); Manzocchi et al. (2008a)). The consequence of under-estimating fault uncertainty may lead to poor field development plans and inappropriate parameter selection in history matching tasks. The sensitivity study suggests that using only a small set of structural interpretations (or scenarios) may not be sufficient to capture the range of reservoir behavior uncertainties. This motivates further research to develop new interpretation and modeling approaches, for instance to integrate well tests early in the uncertainty assessment methodology to see if these allow to rule out some unrealistic structural scenarios. 


\section{Acknowledgments}

We would like to thank Atle Rotevatn and two anonymous reviewers for their constructive comments which helps us improve this paper. This work has been performed in the framework of the RING project managed by ASGA, University of Lorraine. We thank the industry and academic members of the Gocad Research Consortium $^{1}$ for supporting this research. We also thank Paradigm for providing the Gocad-SKUA software and API which was used to implement the downscaling and gridding codes presented in this paper. We also thank Schlumberger for providing the ECLIPSE software used for the flow simulations.

\section{References}

Abrahamsen, P., 1992, Bayesian kriging for seismic depth conversion of a multi-layer reservoir: Geostatistics Tróia '92. Volume 1. Fourth International Geostatistical Congress. Tróia, Portugal, 13-18 September, 1992, Kluwer Academic Publ., 385398.

Bastesen, E., and A. Rotevatn, 2012, Evolution and structural style of relay zones in layered limestone-shale sequences: insights from the Hammam Faraun fault block, Suez Rift, Egypt: Journal of the Geological Society, 169, 477-488.

Bense, V. F., and R. Van Balen, 2004, The effect of fault relay and clay smearing on groundwater flow patterns in the Lower Rhine Embayment: Basin Research, 16, 397-411.

Bond, C., A. Gibbs, Z. Shipton, and S. Jones, 2007, What do you think this is? "conceptual uncertainty" in geoscience interpretation: GSA Today, 17, 4-10.

\footnotetext{
${ }^{1}$ http://www.ring-team.org/index.php/consortium/members
} 
Bond, C. E., 2015, Uncertainty in structural interpretation: Lessons to be learnt: Journal of Structural Geology, 74, 185 - 200.

Cartwright, J. A., B. D. Trudgill, and C. S. Mansfield, 1995, Fault growth by segment linkage: an explanation for scatter in maximum displacement and trace length data from the Canyonlands Grabens of SE Utah: Journal of Structural Geology, 17, 1319-1326.

Caumon, G., P. Collon-Drouaillet, C. Le Carlier de Veslud, S. Viseur, and J. Sausse, 2009, Surface-based 3D modeling of geological structures: Mathematical Geosciences, 41, no. 8, 927-945.

Childs, C., J. Watterson, and J. J. Walsh, 1995, Fault overlap zones within developing normal fault systems: Journal of the Geological Society, 152, 535-549.

Cowie, P. A., and C. H. Scholz, 1992, Displacement-length scaling relationship for faults: data synthesis and discussion: Journal of Structural Geology, 14, 11491156.

Fachri, M., A. Rotevatn, and J. Tveranger, 2013, Fluid flow in relay zones revisited: Towards an improved representation of small-scale structural heterogeneities in flow models: Marine and Petroleum Geology, 46, 144-164.

Faure Walker, J., G. Roberts, P. Cowie, I. Papanikolaou, P. Sammonds, A. Michetti, and R. Phillips, 2009, Horizontal strain-rates and throw-rates across breached relay zones, central Italy: Implications for the preservation of throw deficits at points of normal fault linkage: Journal of Structural Geology, 31, 1145-1160.

Fossen, H., and J. Hesthammer, 2000, Possible absence of small faults in the Gullfaks Field, northern North Sea: implications for downscaling of faults in some porous sandstones: Journal of Structural Geology, 22, 851-863.

Georgsen, F., P. Røe, A. R. Syversveen, and O. Lia, 2012, Fault displacement mod- 
elling using 3D vector fields: Computational Geosciences, 16, 247-259.

Giba, M., J. Walsh, and A. Nicol, 2012, Segmentation and growth of an obliquely reactivated normal fault: Journal of Structural Geology, 39, 253-267.

Gringarten, E., G. Arpat, Burc, M. A. Haouesse, A. Dutranois, L. Deny, S. Jayr, A.-L. Tertois, J.-L. Mallet, A. Bernal, and L. X. Nghiem, 2008, New grids for robust reservoir modeling: Presented at the SPE Annual Technical Conference and Exhibition, SPE.

Jolley, S., D. Barr, J. Walsh, and R. Knipe, 2007, Structurally complex reservoirs: an introduction: Geological Society, London, Special Publications, 292, 1-24.

Julio, C., G. Caumon, and M. Ford, 2015, Sampling the uncertainty associated with segmented normal fault interpretation using a stochastic downscaling method: Tectonophysics, 639, 56-67.

Kattenhorn, S. A., and D. D. Pollard, 2001, Integrating 3-D seismic data, field analogs, and mechanical models in the analysis of segmented normal faults in the Wytch Farm oil field, southern England, United Kingdom: AAPG bulletin, 85, $1183-1210$.

Kim, Y.-S., D. C. Peacock, and D. J. Sanderson, 2004, Fault damage zones: Journal of Structural Geology, 26, 503-517.

Laurent, G., G. Caumon, A. Bouziat, and M. Jessell, 2013, A parametric method to model 3D displacements around faults with volumetric vector fields: Tectonophysics, 590, 83-93.

Mallet, J.-L., 1988, Three dimensional graphic display of disconnected bodies: Mathematical geology, 122, 977-990.

Mallison, B., C. Sword, T. Viard, W. Milliken, and A. Cheng, 2014, Unstructured cut-cell grids for modeling complex reservoirs: SPE Journal, 19, 340-352. 
Manzocchi, T., C. Childs, and J. J. Walsh, 2010, Faults and fault properties in hydrocarbon flow models: Geofluids, 10, 94-113.

Manzocchi, T., A. Heath, J. Walsh, and C. Childs, 2002, The representation of two phase fault-rock properties in flow simulation models: Petroleum Geoscience, 8, $119-132$

Manzocchi, T., A. E. Heath, B. Palananthakumar, C. Childs, and J. J. Walsh, 2008a, Faults in conventional flow simulation models: a consideration of representational assumptions and geological uncertainties: Petroleum Geoscience, 14, 91-110.

Manzocchi, T., J. D. Matthews, J. A. Strand, J. N. Carter, A. Skorstad, J. A. Howell, K. D. Stephen, and J. J. Walsh, 2008b, A study of the structural controls on oil recovery from shallow-marine reservoirs: Petroleum Geoscience, 14, 55-70.

Manzocchi, T., J. Walsh, P. Nell, and G. Yielding, 1999, Fault transmissibility multipliers for flow simulation models: Petroleum Geoscience, 5, 53-63.

Manzocchi, T., J. J. Walsh, M. Tomasso, J. Strand, C. Childs, and P. Haughton, 2007, Static and dynamic connectivity in bed-scale models of faulted and unfaulted turbidites: Structurally Complex Reservoirs, Geological Society of London, 309336.

Matthäi, S. K., S. Geiger, S. G. Roberts, A. Paluszny, M. Belayneh, A. Burri, A. Mezentsev, H. Lu, D. Coumou, T. Driesner, and C. A. Heinrich, 2007, Numerical simulation of multi-phase fluid flow in structurally complex reservoirs: Geological Society, London, Special Publications, 292, 405-429.

Merland, R., G. Caumon, B. Lévy, and P. Collon-Drouaillet, 2014, Voronoi grids conforming to 3D structural features: Computational Geosciences, 18, 373-383.

Micarelli, L., I. Moretti, M. Jaubert, and H. Moulouel, 2006, Fracture analysis in the south-western Corinth rift (Greece) and implications on fault hydraulic behavior: 
Tectonophysics, 426, 31-59.

Mustapha, H., R. Dimitrakopoulos, T. Graf, and A. Firoozabadi, 2011, An efficient method for discretizing 3D fractured media for subsurface flow and transport simulations: International Journal for Numerical Methods in Fluids, 67, 651-670. Myers, R., A. Allgood, A. Hjellbakk, P. Vrolijk, and N. Briedis, 2007, Testing fault transmissibility predictions in a structurally dominated reservoir: Ringhorne Field, Norway: Structurally Complex Reservoirs, Geological Society of London, $271-294$.

Paluszny, A., S. K. Matthai, and M. Hohmeyer, 2007, Hybrid finite element finite volume discretization of complex geologic structures and a new simulation workflow demonstrated on fractured rocks: Geofluids, 7, 186-208.

Peacock, D., and D. Sanderson, 1991, Displacements, segment linkage and relay ramps in normal fault zones: Journal of Structural Geology, 13, 721-733.

Pellerin, J., B. Lévy, and G. Caumon, 2014, Toward mixed-element meshing based on restricted Voronoi diagrams: Procedia Engineering, 82, 279-290.

Pyrcz, M. J., and C. V. Deutsch, 2014, Geostatistical reservoir modeling: Oxford university press.

Rotevatn, A., S. J. Buckley, J. A. Howell, and H. Fossen, 2009a, Overlapping faults and their effect on fluid flow in different reservoir types: A LIDAR-based outcrop modeling and flow simulation study: AAPG bulletin, 93, 407-427.

Rotevatn, A., H. Fossen, J. Hesthammer, T. E. Aas, and J. A. Howell, 2007, Are relay ramps conduits for fluid flow? Structural analysis of a relay ramp in Arches National Park, Utah: Presented at the Fractures Reservoirs, Geological Society of London.

Rotevatn, A., J. Tveranger, J. Howell, and H. Fossen, 2009b, Dynamic investigation 
of the effect of a relay ramp on simulated fluid flow: geocellular modelling of the Delicate Arch Ramp, Utah: Petroleum Geoscience, 15, 45-58.

Sanderson, D. J., and C. W. Nixon, 2015, The use of topology in fracture network characterization: Journal of Structural Geology.

Soliva, R., and A. Benedicto, 2004, A linkage criterion for segmented normal faults: Journal of Structural Geology, 26, 2251-2267.

Thore, P., A. Shtuka, M. Lecour, T. Ait Ettajer, and R. Cognot, 2002, Structural uncertainties: determination, management and applications: Geophysics, 67, 840-852.

Walsh, J. J., W. R. Bailey, C. Childs, A. Nicol, and C. G. Bonson, 2003, Formation of segmented normal faults: a 3-D perspective: Journal of Structural Geology, 25, $1251-1262$.

Zehner, B., J. H. Brner, I. Grz, and K. Spitzer, 2015, Workflows for generating tetrahedral meshes for finite element simulations on complex geological structures: Computers \& Geosciences, 79, 105-117. 


\section{List of Figures}

1 Schematic representation of the overlap ramp between two left-stepping en-echelon segments (a) Unbreached relay ramp between the two segments. (b) Breached relay ramp linking the two segments. . . . . . . 27

2 Data set composed of the fault $\mathcal{F}$, two horizon point sets and two wells. (a) 3D view of the reservoir data. (b) Top view of the reservoir data indicating location of the cross-section in Fig. 6. . . . . . . . 28

3 A few segmentation configurations obtained from the downscaling of the fault $\mathcal{F}($ Julio et al., 2015) . . . . . . . . . . . . . . . . 29

4 Schematic representation in cross section of the horizon geometry conditioning in overlap zones. (a) Variation of the parameter $\beta$ that characterizes the ratio between the relay fault throw and the total vertical displacement. (b) Data points conditioning the interpolation of the horizon geometries in a relay zone. . . . . . . . . . . . . . 30

5 Example of a reservoir model composed of the fault $\mathcal{F}$ before downscaling (a) Relative depth variation in the reservoir model. (b) Porosity distribution in the reservoir model. . . . . . . . . . . . . . . 31

6 Cross-section across the monoclinal reservoir structure showing the initial oil saturation and oil-water contact. . . . . . . . . . . . . . 32

$7 \quad$ Evolution of the oil saturation for four different segmentation configurations (a) Fault $\mathcal{F}$ before downscaling. (b) Two hard-linked leftstepping segments. (c) Three soft-linked segments. (d) Two softlinked right-stepping segments. . . . . . . . . . . . . . . 33

8 Initial oil in place of the stochastic models in our case study. . . . . 34 
9 Histograms of the water cut after 30 years of production computed from the downscaled models. . . . . . . . . . . . . . . 35

10 Evolution of the water cut as a function of time for the wells $w_{1}(\mathrm{a}, \mathrm{c}, \mathrm{e})$ and $w_{2}(\mathrm{~b}, \mathrm{~d}, \mathrm{f})(\mathrm{a})$ and (b) The red curve corresponds to the water cut evolution of the model composed of the fault $\mathcal{F}$ before downscaling. The black curves are water cuts for models with downscaled faults. (c) and (d) Comparison between models composed of two soft-linked right-stepping segments and models composed of two hard-linked leftstepping segments. (e) and (f) Comparison between models composed of two soft-linked right-stepping segments and models composed of three soft-linked segments. (g) and (h) Comparison between models composed of two different configurations of three soft-linked segments. 36

11 Statistics on the water breakthrough time according to the segmentation configurations. We have considered that the water breakthrough is reached when the water cut becomes superior to 0.01. (a) Well $w_{1}$. (b) Well $w_{2} . \quad \ldots \ldots \ldots 7$. . . . . . . . . . . . . . . . . . 37

\section{List of Tables}

1 Flow simulation parameters . . . . . . . . . . . . . 38 


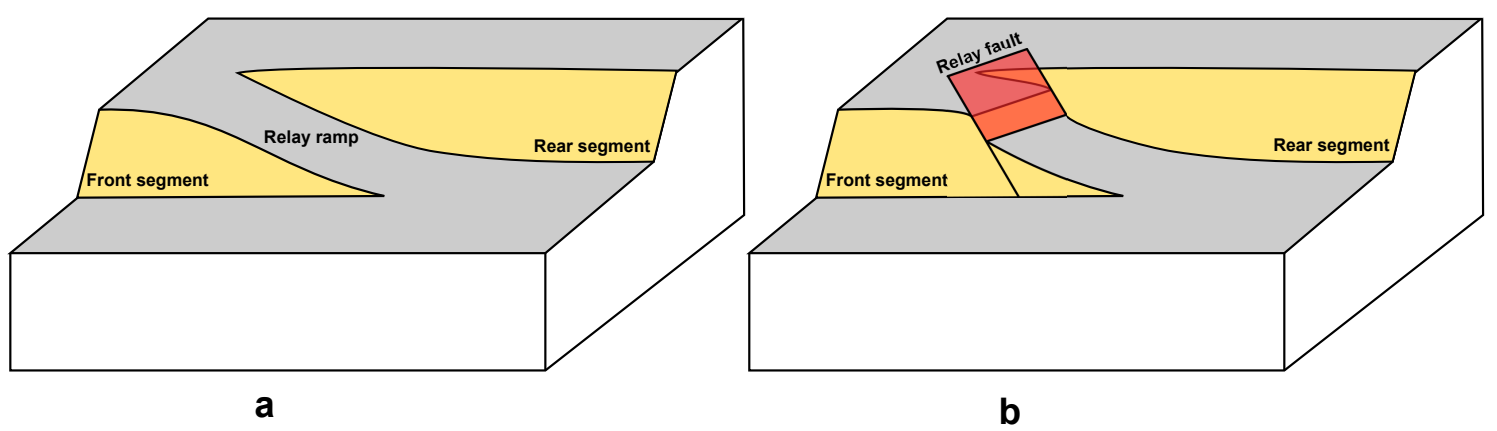

Figure 1: Schematic representation of the overlap ramp between two left-stepping en-echelon segments (a) Unbreached relay ramp between the two segments. Breached relay ramp linking the two segments. 

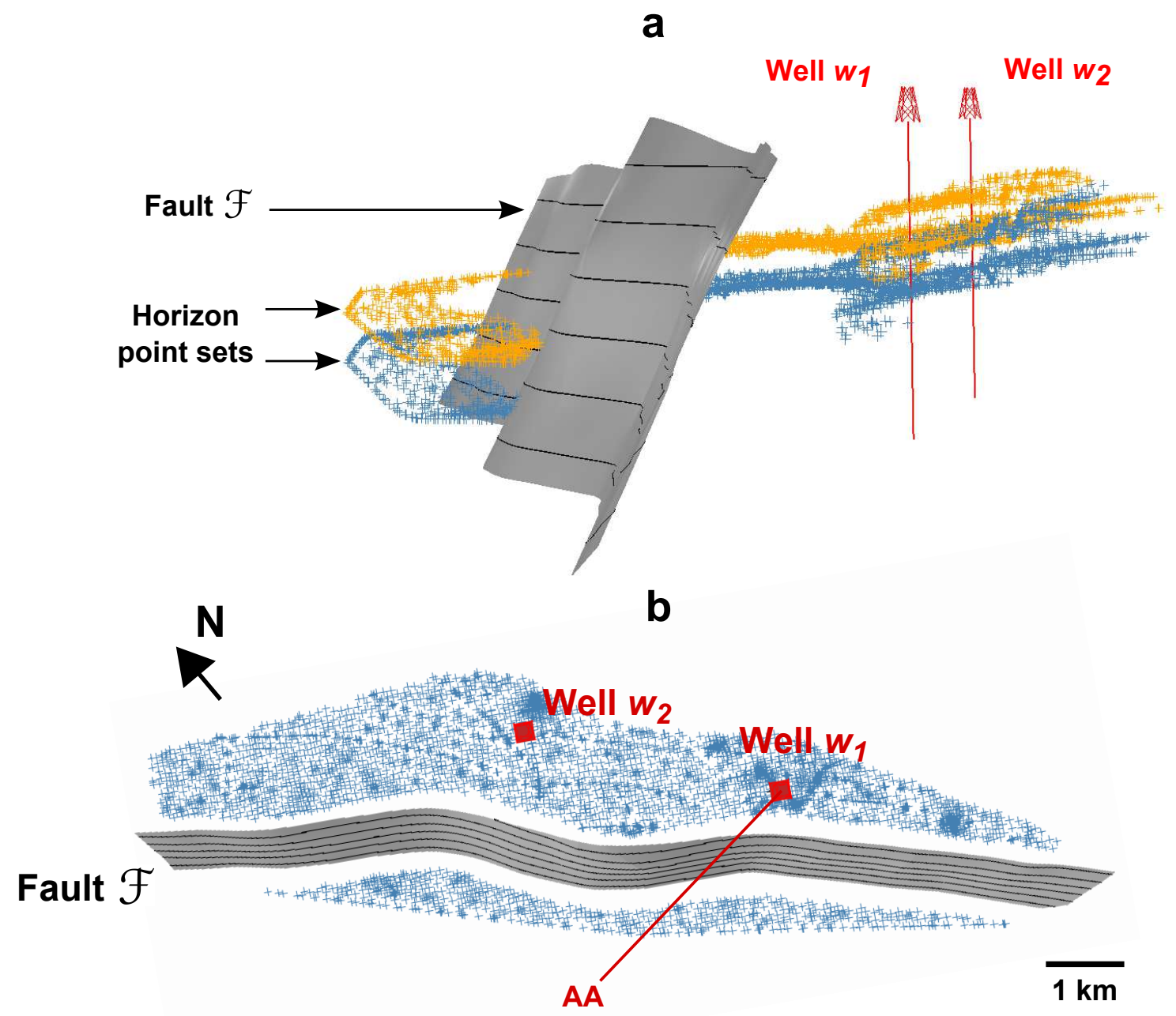

Figure 2: Data set composed of the fault $\mathcal{F}$, two horizon point sets and two wells. (a) 3D view of the reservoir data. (b) Top view of the reservoir data indicating location of the cross-section in Fig. 6. 


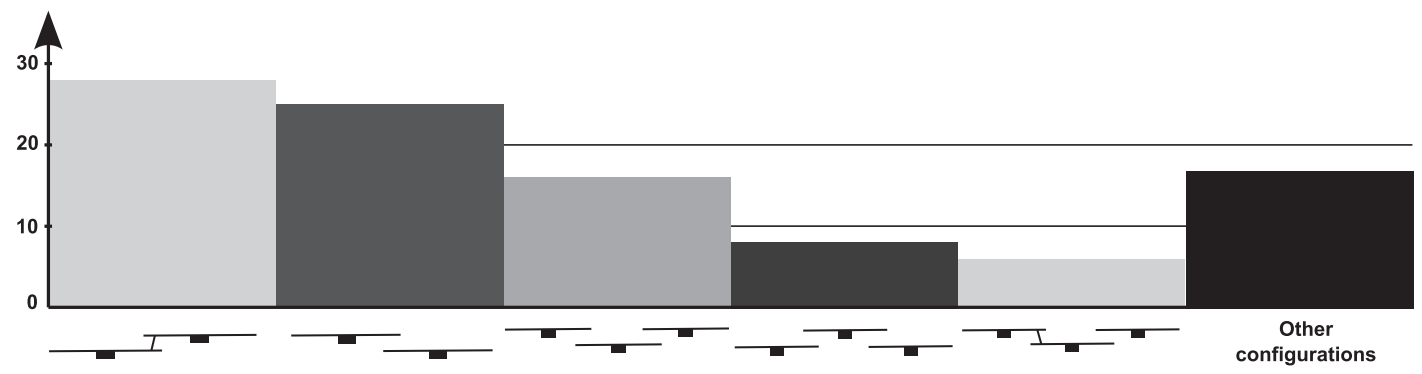

Figure 3: A few segmentation configurations obtained from the downscaling of the fault $\mathcal{F}$ (Julio et al., 2015) 
a

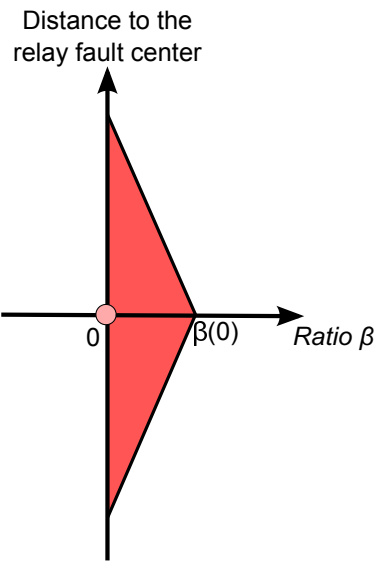

b

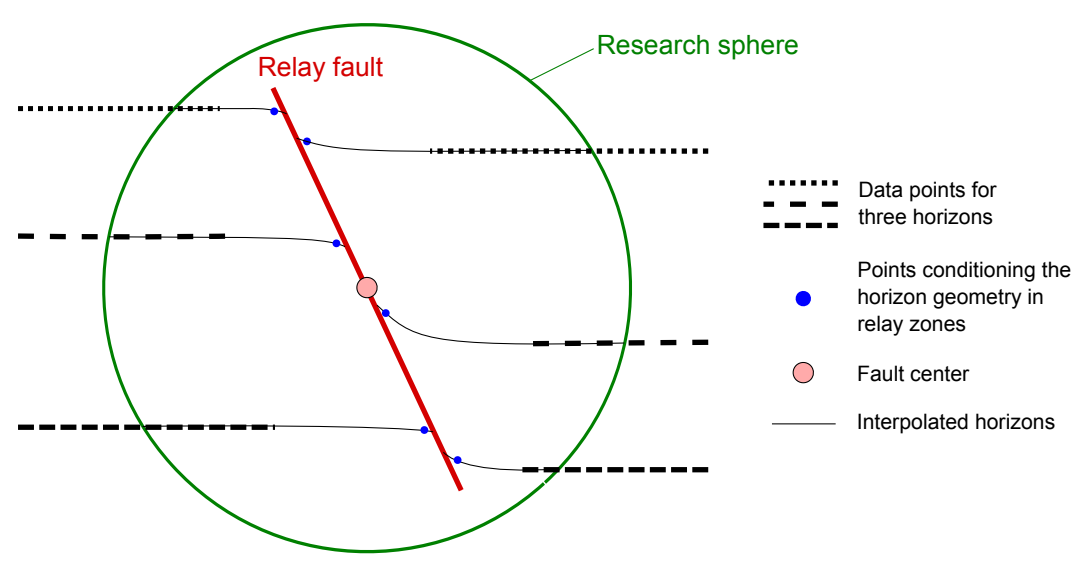

Figure 4: Schematic representation in cross section of the horizon geometry conditioning in overlap zones. (a) Variation of the parameter $\beta$ that characterizes the ratio between the relay fault throw and the total vertical displacement. (b) Data points conditioning the interpolation of the horizon geometries in a relay zone. 

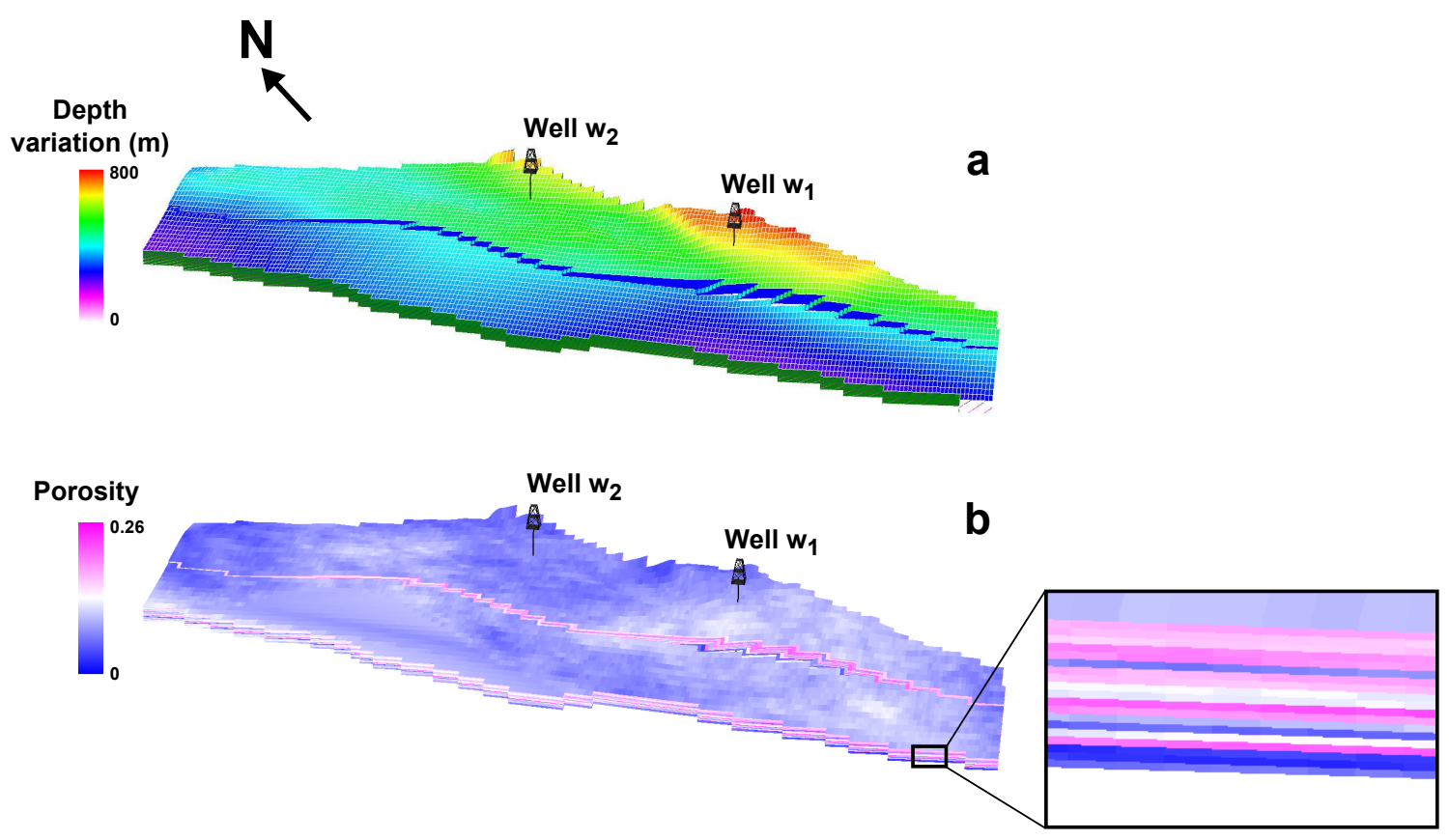

Figure 5: Example of a reservoir model composed of the fault $\mathcal{F}$ before downscaling

(a) Relative depth variation in the reservoir model. (b) Porosity distribution in the reservoir model. 


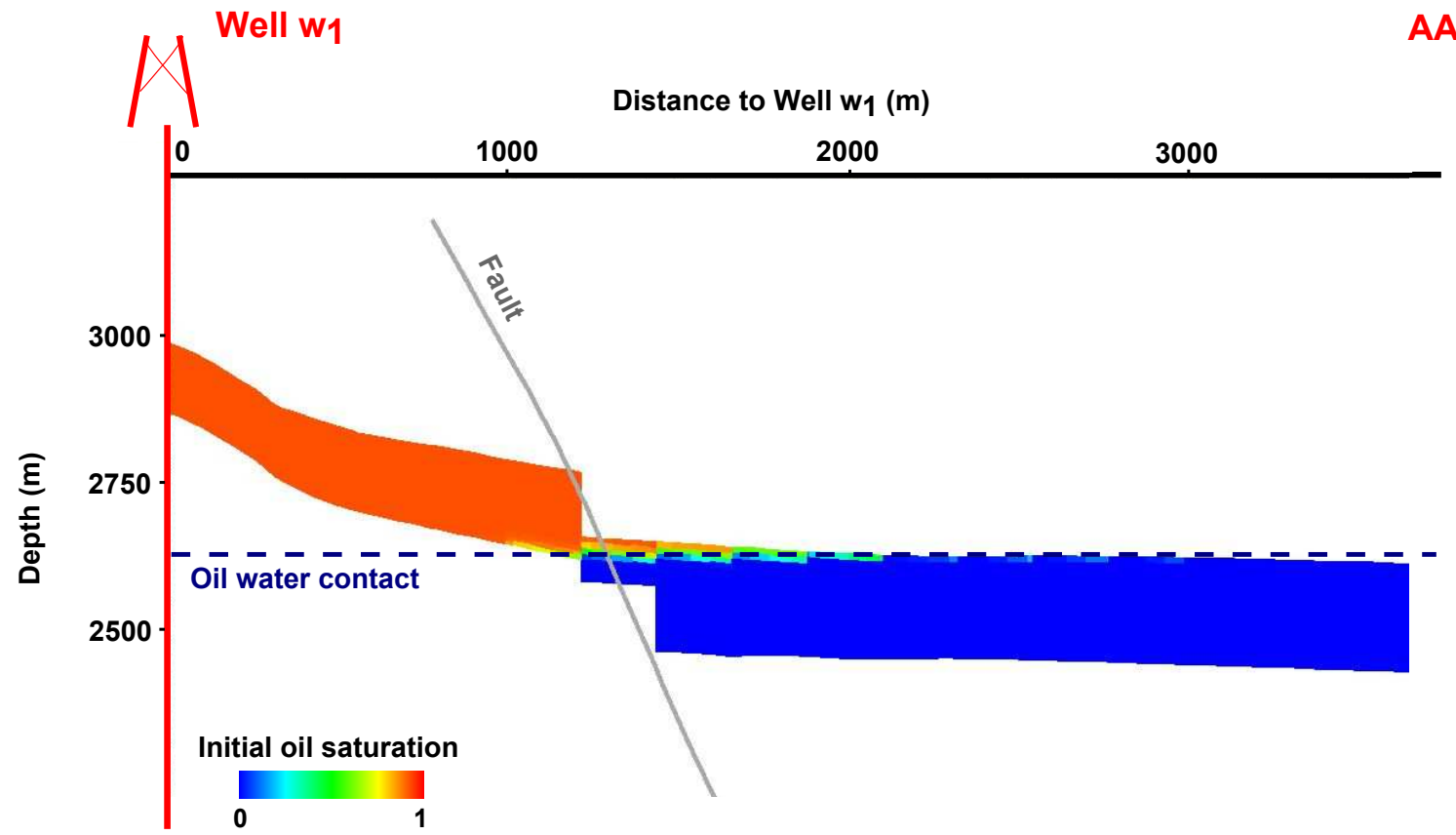

Figure 6: Cross-section across the monoclinal reservoir structure showing the initial oil saturation and oil-water contact. 


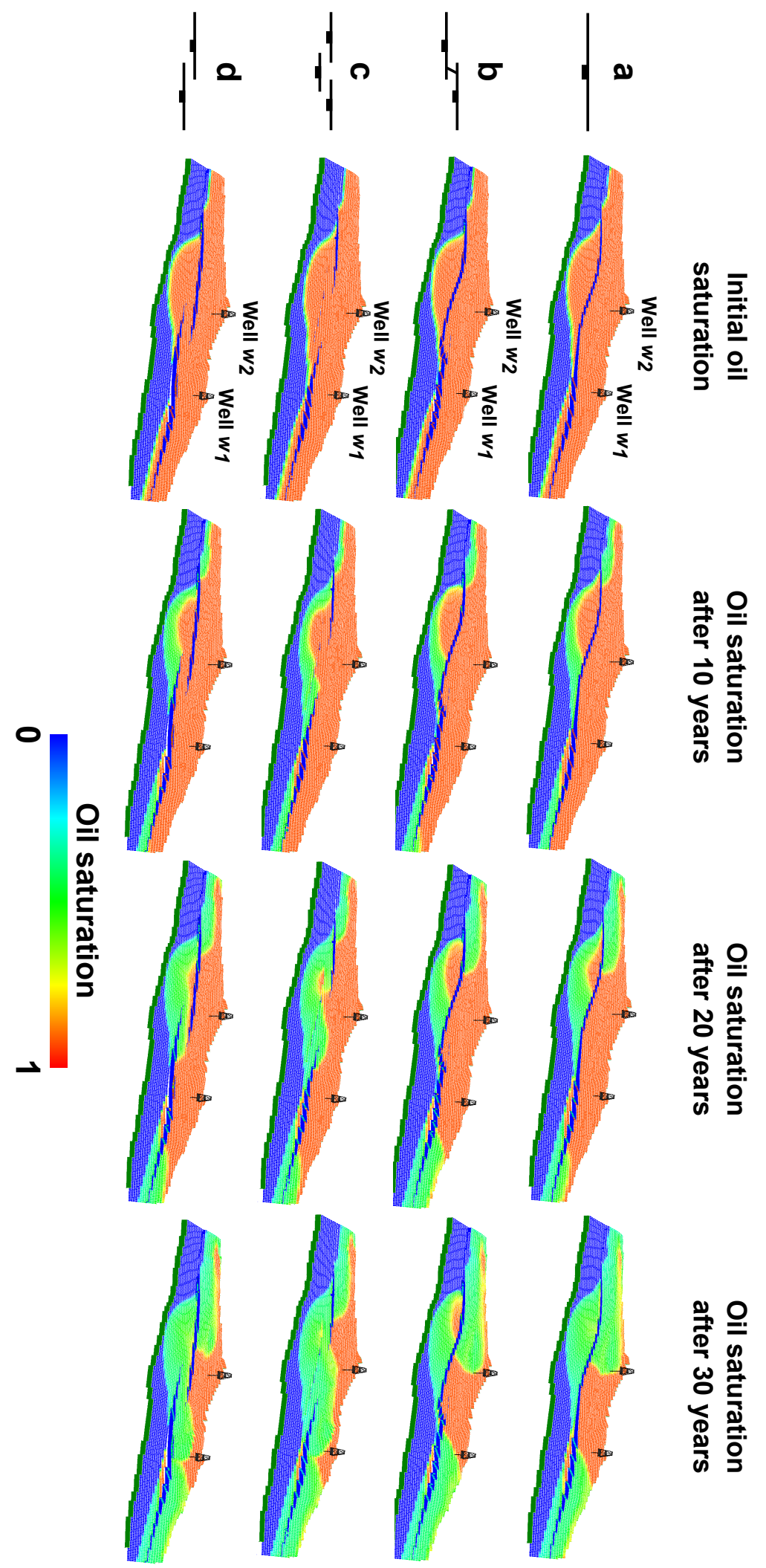

Figure 7: Evolution of the oil saturation 33 for four different segmentation configurations (a) Fault $\mathcal{F}$ before downscaling. (b) Two hard-linked left-stepping segments. (c) Three soft-linked segments. (d) Two soft-linked right-stepping segments. 


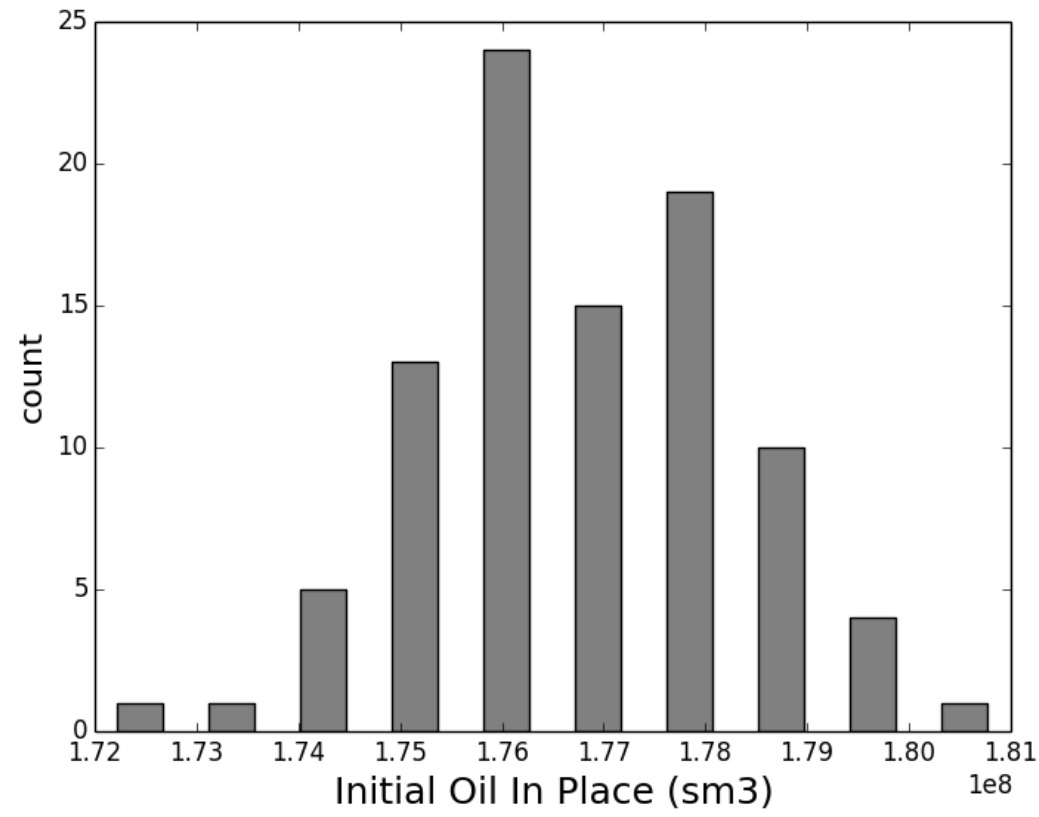

Figure 8: Initial oil in place of the stochastic models in our case study. 

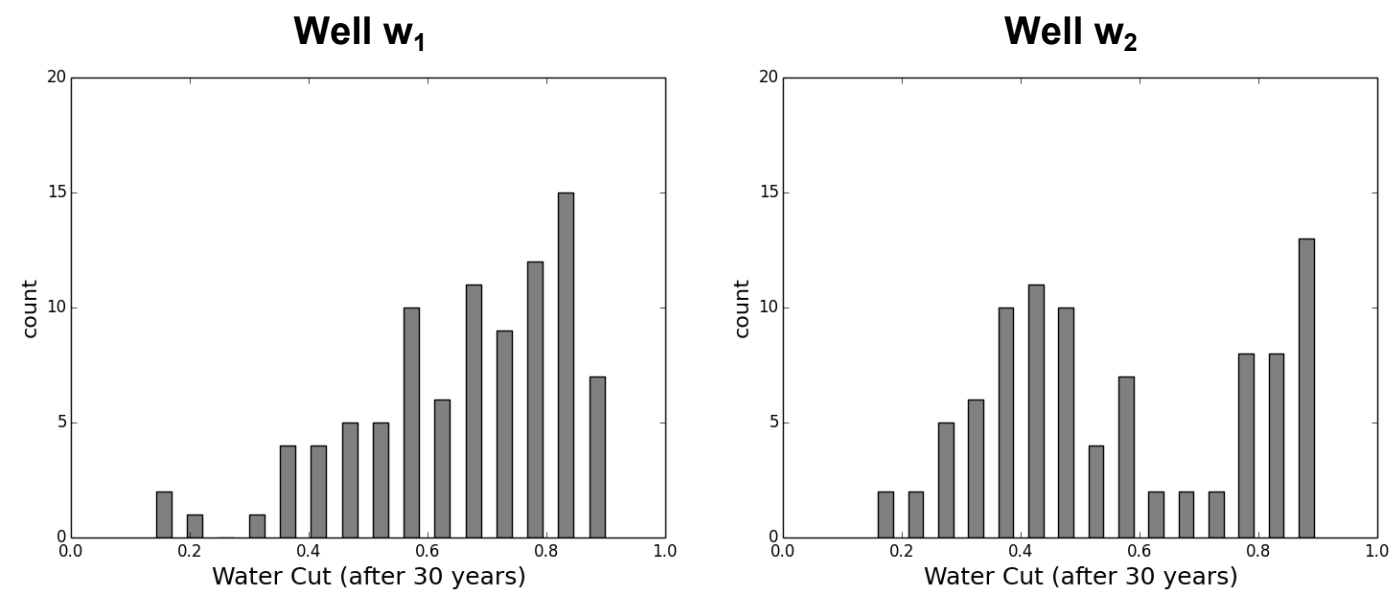

Figure 9: Histograms of the water cut after 30 years of production computed from the downscaled models. 

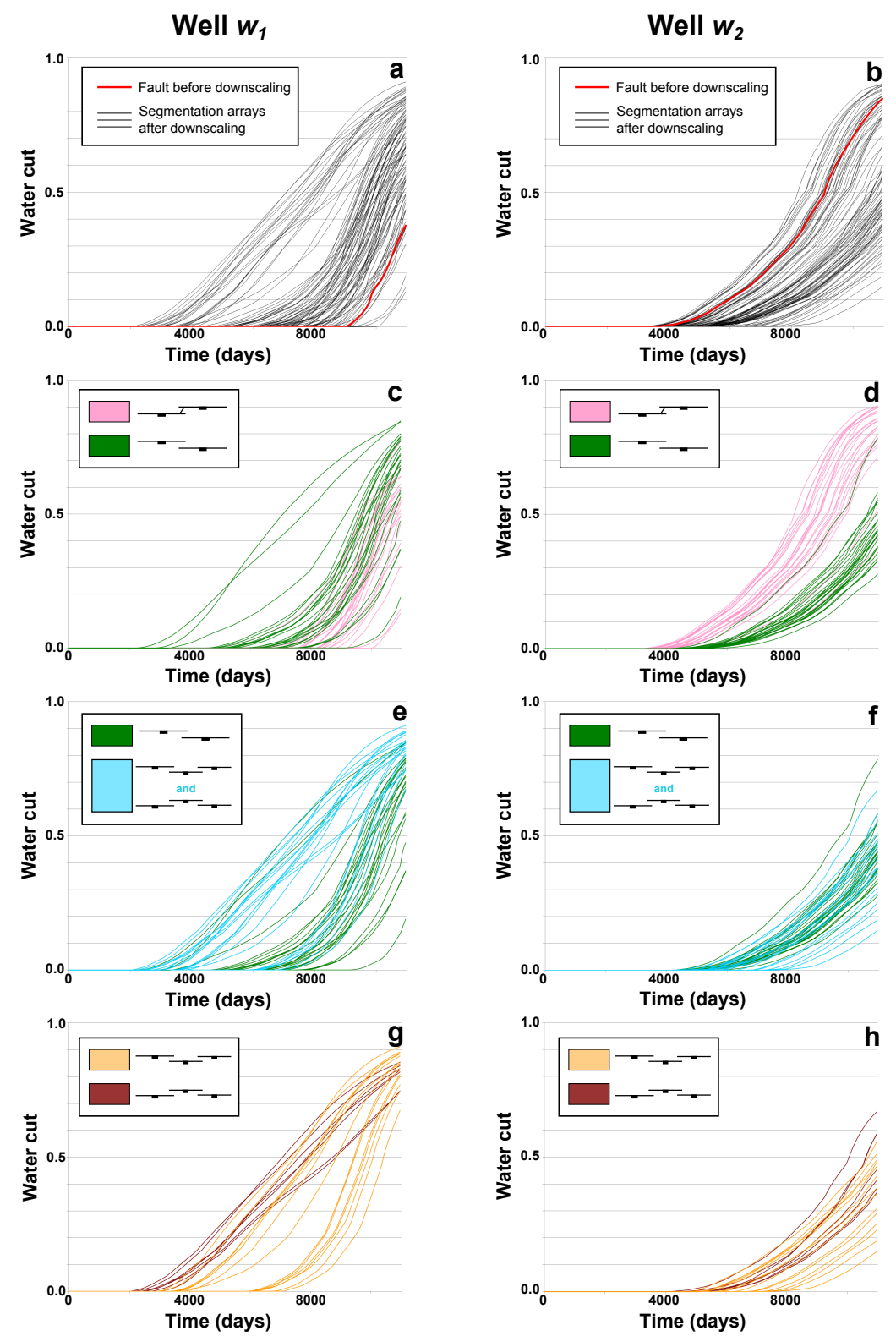

Figure 10: Evolution of the water cut as a function of time for the wells $w_{1}$ (a,c,e) and $w_{2}(\mathrm{~b}, \mathrm{~d}, \mathrm{f})(\mathrm{a})$ and $(\mathrm{b})$ The red curve corresponds to the water cut evolution of the model composed of the fault $\mathcal{F}$ before downscaling. The black curves are water cuts for models with downscaled faults. (c) and (d) Comparison between models composed of two soft-linked right-stepping segments and models composed of two hard-linked left-stepping segments. (e) and (f) Comparison between models composed of two soft-linked right-steppirgs segments and models composed of three soft-linked segments. (g) and (h) Comparison between models composed of two different configurations of three soft-linked segments. 


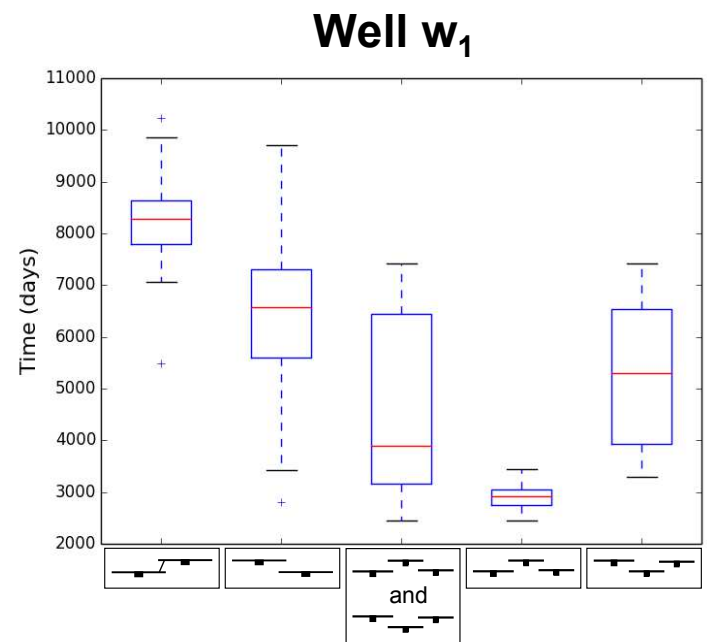

a

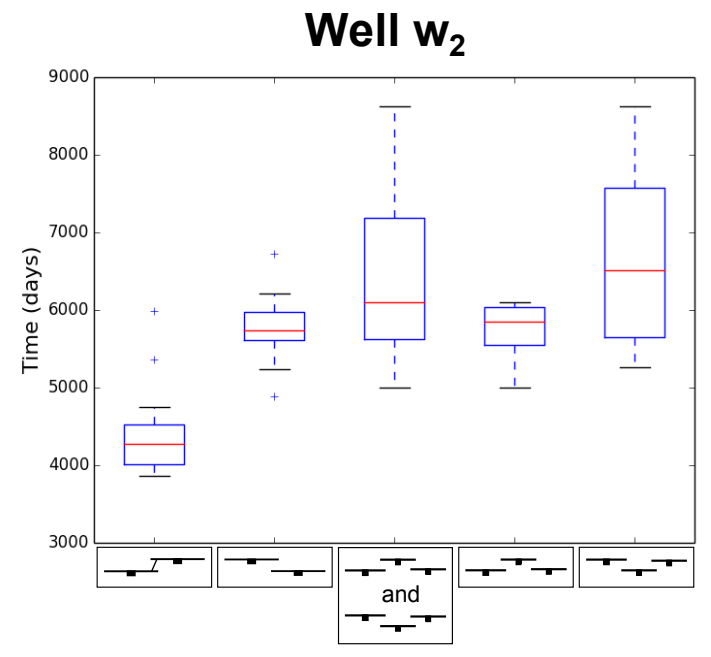

b

Figure 11: Statistics on the water breakthrough time according to the segmentation configurations. We have considered that the water breakthrough is reached when the water cut becomes superior to 0.01. (a) Well $w_{1}$. (b) Well $w_{2}$. 


\begin{tabular}{lcc}
\hline Run time & 30 years \\
\hline Initial fluids & water, oil \\
\hline Aquifer & Carter-Tracy model \\
Inner radius & $50,000 \mathrm{~m}$ \\
Thickness & $100 \mathrm{~m}$ \\
Permeability & $300 \mathrm{mD}$ \\
Porosity & & 0.18 \\
\hline Wells & & producers $\left(w_{1}\right.$ and $\left.w_{2}\right)$ \\
Initial control & $w_{1}$ & Oil rate target control \\
& $w_{2}$ & Oil rate target control \\
Oil rate target & $w_{1}$ & $4500 \mathrm{sm}^{3} /$ day \\
& $w_{2}$ & $3500 \mathrm{sm}^{3} /$ day \\
Lower BHP limit & $w_{1}$ & 100 barsa \\
& $w_{2}$ & 100 barsa \\
\hline
\end{tabular}

Table 1: Flow simulation parameters 